\title{
Biofilm Formation and $\beta$-lactamase Enzymes: A Synergism Activity in Acinetobacter baumannii Isolated from Wound Infection
}

\author{
Mahyar Porbaran $^{1}$ (D), Reza Habibipour ${ }^{1 *}$ iD
}

1. Department of Microbiology, Faculty of Basic Sciences, Hamedan Branch, Islamic Azad University, Hamedan, Iran

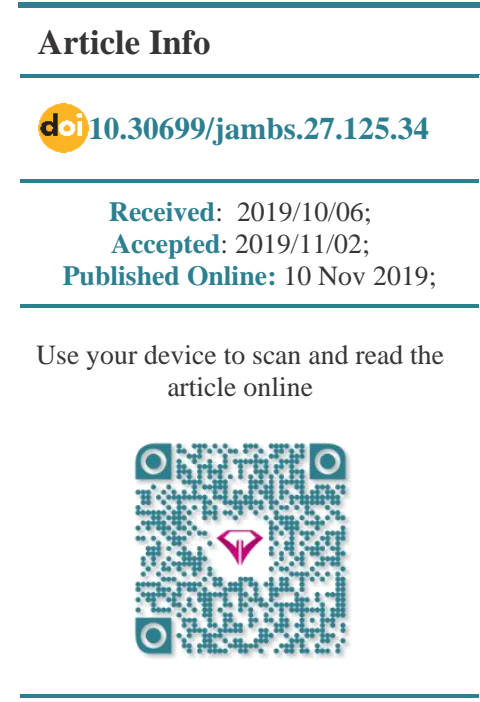

Corresponding Information: Reza Habibpour, Dept. of Microbiology, Faculty of Basic Sciences, Hamedan Branch, Islamic Azad University, Hamedan, Iran E-Mail: Habibipour@iauh.ac.ir

\begin{abstract}
Background \& Objective: Biofilm formation plays a crucial role in wound infections and increases the bacteria resistance to treatment. The present study investigated the relationship between the biofilm formation, ESBL, AmpC, and KPC enzymes in Acinetobacter baumannii isolated from the wound specimens.
\end{abstract}

Materials \& Methods: Eighty- nine A. baumannii isolates were collected from wound specimens and were confirmed by different biochemical tests. The biofilm-producing strains were identified using the crystal violet method. The producing strains of KPC, ESBL, and AmpC $\beta$-lactamase enzymes were detected through phenotypic tests. Further, the PCR method was employed to identify the ESBL, KPC, and AmpC. The Chi-square test and SPSS 16 were used for data analysis.

Results: Among 89 wound isolates, 21 and 68 were collected from male and female patients, respectively. The strains resistant to ciprofloxacin (69.66\%) and gentamicin (66.29\%) were the most frequent strains while ceftazidime (7.86\%) and colistin $(1.12 \%)$ resistant strains had the lowest frequency. Furthermore, 40 isolates were considered as ESBL-producing enzymes, 33 isolates as AmpC, and 26 isolates as KPC-producing enzymes. In addition, the isolates were categorized as strong biofilms with 20 isolates, moderate biofilms with 19 isolates, and weak biofilm-producing strains with 10 isolates. The distribution of the $\beta$-lactamase genes in A. baumannii isolates was bla VEB (34.83\%), blaPER (32.58\%), blaFOX (29.21\%), blaADC (30.33\%), blaIMP $(28.08 \%)$, and blaKPC (22.47\%).

Conclusion: Our results demonstrated that isolates with a higher level of antibiotic resistance tended to form stronger biofilms. Likewise, the results showed that the relationship between biofilm formation and antibiotic resistance might be affected by the type of $\beta$-lactamase enzyme in wound infection.

Keywords: Acinetobacter baumannii, $\beta$-lactamases, Biofilm, Bacterial Infections, Drug Resistance

Copyright $\odot$ 2019, This is an original open-access article distributed under the terms of the Creative Commons Attribution-noncommercial 4.0 International License which permits
copy and redistribution of the material just in noncommercial usages with proper citation.

\section{Introduction}

Acinetobacter baumannii is a non-fermenting and gram-negative bacillus which has a central effect in wound infections (1). The mortality rate among the hospitalized patients infected with multidrug-resistant (MDR) A. baumannii is high, especially when they receive improper experimental treatments $(\mathbf{1 , 2})$. Prolonged hospitalization, along with the use of a catheter and other medical devices, increases the possibility of contamination with A. baumannii (3).

The biofilm, as a virulence factor, protects $A$. baumannii from the effect of antimicrobial agents and disinfectants. Biofilm-forming A. baumannii can tolerate high concentrations of antibiotics, which eventually results in failing the treatment $(2,3)$. Therefore, this factor can lead to wound and medical device-related infections in the patients who have been hospitalized for a long time $(4,5)$. In addition, the biofilm creates an ideal environment for the horizontal transmission of various genes involved in the pathogenicity and antibiotic resistance of the bacterium (6). Accordingly, A. baumannii can develop some slow-dividing persistent cells in deep layers, which are tolerant of antimicrobials $(\mathbf{7 , 8})$. However, one of the main reasons why A. baumannii is prevalent in clinical environment can be attributed to its ability to form a biofilm (9).

$\beta$-lactamases confer resistance to various $\beta$-lactam antibiotics in $A$. baumannii by inactivating the drug. In the primary sequence of $\beta$-lactamases, Ambler proposed a new classification based on homology (10, 11). The Ambler class A, C, and D $\beta$-lactamases are termed serine $\beta$-lactamases as they possess a serine residue in their active site, which binds to the $\beta$-lactam ring. The class B $\beta$-lactamases are called zinc metalloenzymes since they possess zinc ions in their active site $(12,13)$. Generally, the majority of class A 
enzymes are susceptible to the most commercially available $\beta$-lactamase inhibitors such as clavulanate. Further, the most frequently encountered class A $\beta$ lactamases include TEM, SHV, CTXM, and KPC (12, 13). Another primary source of $\beta$-lactam resistance in bacterial pathogens is class $\mathrm{C} \beta$-lactamases. The clinically significant $\beta$-lactamases ADC, AmpC, $\mathrm{CMY}$, and FOX are considered as the members of the class $C$ family $(\mathbf{1 4}, \mathbf{1 5})$. In addition, $\beta$-lactamases of class $\mathrm{D}$, as in classes $\mathrm{A}$ and $\mathrm{C}$, are serine enzymes although the catalytic mechanism of these $\beta$-lactamases is significantly different (10).

Despite the fact that several studies have reported that there is a relationship between biofilm formation and antibiotic resistance (4), some environmental factors may change the biofilm formation and the activity of $\beta$-lactamase enzymes $(\mathbf{1 0 , 1 6 )}$. In other words, the presence of the ESBLs and AmpC enzymes may result in altering the biological activity of the organism and increasing the pathogenicity and spread of the infection. Therefore, the present study aimed to investigate the relationship between the biofilm formation and the prevalence of different $\beta$-lactamase enzymes in A. baumannii strains.

\section{Materials and Methods}

\section{Study Design and Collecting Isolates}

Eighty-nine A. baumannii isolates were collected from January 2018 until March 2019 from the patients in pediatric burn centers, burn care, and burn surgery and resuscitation centers at hospitals located in Hamedan, Iran including the Sina Hospital. First, the isolates were phenotypically identified using the standard microbiological techniques and biochemical tests. All the isolates were subcultured on MacConkey agar (Merck, Germany) and incubated overnight at $37^{\circ} \mathrm{C}$. Next, a single colony was transferred into the nutrient broth (Merck, Germany) and was incubated overnight at $37^{\circ} \mathrm{C}$ with agitation. In addition, oxidase test, motility, and biochemical reactions such as indole production, MR/VP test, mannitol fermentation, urea hydrolysis, and aesculin hydrolysis were conducted on the isolates. Then, all the isolates were confirmed using the $16 s r R N A$ gene. Finally, $100 \mu \mathrm{L}$ of the overnight culture was mixed with $900 \mu \mathrm{L}$ of $100 \mathrm{w} / \mathrm{w}$ glycerol and was stored at $-80^{\circ} \mathrm{C}$.

\section{Determining the Antibiotic Resistance Pattern}

The antibiotic resistance patterns in A. baumannii isolates were identified using the disk diffusion method based on the Clinical Laboratory Standards Institute (CLSI 2018) protocol. Different antibacterial disks such as doripenem $(10 \mu \mathrm{g})$, meropenem $(10 \mu \mathrm{g})$, imipenem $(10 \mu \mathrm{g})$, piperacillin $(30 \mu \mathrm{g})$, cefepime $(10 \mu \mathrm{g})$, ceftazidime $(30 \mu \mathrm{g})$, gentamicin $(30 \mu \mathrm{g})$, amikacin $(10 \mu \mathrm{g})$, ciprofloxacin $(5 \mu \mathrm{g})$, and levofloxacin $(30 \mu \mathrm{g})$ were performed (17). All the discs were obtained from MAST UK. In this regard, $A$. baumannii ATCC19606, Escherichia coli ATCC25922, and Klebsiella pneumoniae ATCC70063 were used as the quality control.

Phenotypic Screening and Confirmation of ESBLs, AmpC, and KPC-producing Strains

ESBL and AmpC-producing strains were identified using the AmpC+ESBL detection set (UK, MAST, code: D68C) based on manufacturer's instructions. The Hodge test was used for detecting the KPC strains (4).

\section{Screening the Biofilm-producing Strains}

The production of biofilm was assessed using a crystal violet microtiter plate assay based on the study conducted by Ghadaksaz et al. (18). To this end, 100 $\mu \mathrm{L}$ of the $24 \mathrm{~h}$ grown culture of $A$. baumannii was added to the wells of 3 quarters of the microtiter plate. Next, fresh uninoculated TSB was added to the remaining 1 quarter. The microtiter plate was incubated for $8 \mathrm{~h}$ at $37^{\circ} \mathrm{C}$. After $24 \mathrm{~h}$ incubation, the supernatant was discarded and $125 \mu \mathrm{L}$ of $0.1 \%$ crystal violet solution was added to each well. The microtiter plate was incubated at room temperature for $15 \mathrm{~min}$. The plate was rinsed 4 times by being submerged in a water tub followed by being shaken out and blotted vigorously on a stack of paper towel in order to remove all the excess cells and dye from the plate. Then, the microtiter plate was turned upside down to dry. The OD of each well was measured at 550 and $595 \mathrm{~nm}$ using the microplate reader. In the present study, $A$. baumannii ATCC 19606 was used as a positive control and the culture medium as a negative control.

\section{DNA and Plasmid Extraction}

The genomic and plasmid DNA was isolated, using the gram-negative kit (CinnaGen, Tehran, Iran) according to the manufacturing protocols, for the repetitive PCR analysis of strains.

\section{Detecting AmpC, ESBL, and KPC Genes}

The primers in Table 1 were employed to amplify the resistance and virulence genes. All PCRs were performed in a total volume of $25 \mu \mathrm{L}$. All the reagents were purchased from Promega (Southampton, UK), except for the primers which were supplied by Pishgam Company (Tehran, Iran). Accordingly, the volume of each reagent per reaction included $12 \mu \mathrm{L}$ of MasterMix2.5X (Fermentas, USA), $0.5 \mu \mathrm{L}$ of $10 \mu \mathrm{M}$ forward primer, $0.5 \mu \mathrm{L}$ of $10 \mu \mathrm{M}$ reverser primer, $1 \mu \mathrm{L}$ of DNA template $(1000 \mathrm{ng})$, and $11 \mu \mathrm{L}$ of SDW (Fermentas, USA). The reactions were conducted using an Eppendorf® PCR System 1001C thermal cycler (Eppendorf, Mastercycler@ 5332, Germany).

The thermocycler temperature set was performed based on Table 1. Further, the PCR products were analyzed using Mini Gel Electrophoresis Systems (Thermo Fisher Scientific, MA, USA) on $1.5 \% \mathrm{w} / \mathrm{v}$ agarose gel with $1 x$ TAE buffer for $95 \mathrm{~min}$ at $85 \mathrm{~V}$. The agarose gel was visualized by GelRed $3 \mathrm{X}$ (Biotium, Fremont, CA) stained in the Bio-Rad Gel 
Documentation System (Bio-Rad Laboratories, CA, USA). Furthermore, E. coli ATCC 25922, $K$. pneumonia ATCC 70063, and Enterobacter Creole NCBT 13406 were used as positive controls for resistant genes.

\section{Statistical Analysis}

SPSS 16 (SPSS Inc., Chicago, IL., USA) was used to analyze data with $\chi 2$ statistical test in order to compare the results.

\section{Results}

Among 89 isolates of A. baumannii, 21 (13.48\%) and $68(76.40 \%)$ isolates were collected from male and female patients, respectively.

\section{Antibiotic Resistance Pattern}

Ciprofloxacin (69.66\%) and gentamicin (66.29\%) were detected with the highest prevalence among $A$. baumannii isolates. The resistance to doripenem, imipenem, and meropenem was found to be 46.06, 33.07 , and $35.95 \%$, respectively. Ceftazidime resistant strains were the least frequent strains. Further, 22 MDR isolates $(31.42 \%)$ and 11 XDR isolates $(15.71 \%)$ were reported. Figure 1 illustrates the antibiotic resistance patterns in detail.

\section{Frequency of ESBL, AmpC, and KPC-producing} Strains

The isolates of $A$. baumannii used in the present study included 40 (44.94\%) ESBL-producing, 33 (37.07\%) AmpC-producing, and 26 (29.21\%) KPCproducing isolates. Moreover, the coexistence of ESBL and AmpC $\beta$-lactamases was detected in 19 isolates (21.34\%), and ESBL and KPC $\beta$ lactamases were identified in 14 isolates (13.48\%). Further, A. baumannii producing both KPC and AmpC $\beta$-lactamases was found in 12 isolates (13.48\%). The frequency of the $\beta$-lactamase enzymes in different strains is presented in Table 2 .

\section{Biofilm Production}

Table 2 indicates that 39 isolates $(43.82 \%)$ are classified as strong biofilms, 27 isolates $(30.33 \%)$ as moderate biofilms, and 10 isolates $(11.23 \%)$ as weak biofilm-producing strains.

Distribution and Prevalence of $\beta$-lactamase and Carbapenemase-producing Genes

As shown in Table 2 and Figure 3, ESBL genes are detected from 26 isolates $(29.21 \%)$. In addition, the data in Table 2 and Figure 3 indicated that blaVEB and blaPER genes were identified from 31 (34.83\%) and 26 $(32.58 \%)$ isolates, respectively. The prevalence of the genes encoding blaFOX and blaADC $\beta$-lactamases was observed in $26(29.21 \%)$ and $27(30.33 \%)$ isolates, respectively. The blaIMP gene was identified in 25 isolates $(28.08 \%)$ and the blaKPC gene in 23 isolates (25.84\%).

Further, 26 isolates (29.21\%) indicated positive PCR product for the AmpC-associated resistance gene blaFOX while 27 isolates $(30.33 \%)$ were positive for the blaADC gene. Furthermore, 25 isolates (28.08\%) showed positive PCR product for the carbapenemaseassociated resistance gene blaIMP gene and 23 isolates (25.84\%) were positive for the blaKPC gene. All the genes were amplified from 20 isolates $(22.47 \%)$.

\section{Statistical Analysis}

Table 2 indicates that the biofilm production is strongly correlated with the antibiotic resistance pattern. As can be seen, there is a significant correlation between the formation of biofilms and the frequency distribution of bla $\mathrm{VEB}$, blaPER, bla $\mathrm{FOX}$, bla $\mathrm{ADC}$, and blaIMP genes $(P \leq 0.05$.). Moreover, the correlation between the biofilm formation and MDR/XDR strains was considered as significant $(P \leq 0.05)$.

Table 1. Oligonucleotide sequences used in this study

\begin{tabular}{|c|c|c|c|c|c|}
\hline Genes & $\begin{array}{r}\text { Primer } \\
\text { names }\end{array}$ & Sequence of Primers & Annealing $\operatorname{Tm}\left({ }^{\circ} \mathrm{C}\right)$ & $\begin{array}{l}\text { Product } \\
\text { size (bp) }\end{array}$ & Ref \\
\hline bla & KPC & $\begin{array}{l}\text { F: GATACCACGTTCCGTCTGG } \\
\text { R: GCAGGTTCCGGTTTTGTCTC }\end{array}$ & $\begin{array}{c}94^{\circ} \mathrm{C}: 5 \mathrm{~min} ; 35 \times\left(94^{\circ} \mathrm{C}: 30 \mathrm{sec}, 58^{\circ} \mathrm{C}:\right. \\
\left.\quad 30 \mathrm{sec}, 72^{\circ} \mathrm{C}: 1 \mathrm{~min}\right) ; 72^{\circ} \mathrm{C}: 5 \mathrm{~min}\end{array}$ & 246 & (16) \\
\hline blaveB & VEB & $\begin{array}{l}\text { F: CGACTTCCATTTCCCGATGC } \\
\text { R: GGACTCTGCAACAAATACGC }\end{array}$ & $\begin{array}{c}94^{\circ} \mathrm{C}: 5 \mathrm{~min} ; 35 \times\left(94^{\circ} \mathrm{C}: 30 \mathrm{sec}, 59^{\circ} \mathrm{C} \text { : }\right. \\
\left.30 \mathrm{sec}, 72^{\circ} \mathrm{C}: 1 \mathrm{~min}\right) ; 72^{\circ} \mathrm{C}: 5 \mathrm{~min}\end{array}$ & 643 & (2) \\
\hline bla PER & PER & $\begin{array}{l}\text { F: GCAACTGCTGCAATACTCGG } \\
\text { R: ATGTGCGACCACAGTACCAG }\end{array}$ & $\begin{array}{l}94^{\circ} \mathrm{C}: 5 \mathrm{~min} ; 35 \times\left(94^{\circ} \mathrm{C}: 30 \mathrm{sec}, 54^{\circ} \mathrm{C} \text { : }\right. \\
\left.\quad 30 \mathrm{sec}, 72^{\circ} \mathrm{C}: 1 \mathrm{~min}\right) ; 72^{\circ} \mathrm{C}: 5 \mathrm{~min}\end{array}$ & 340 & (2) \\
\hline bla & FOX & $\begin{array}{l}\text { F: } \\
\text { AACATGGGGTATCAGGGAGATG } \\
\text { R: CAAAGCGCGTAACCGGATTGG }\end{array}$ & $\begin{array}{c}94^{\circ} \mathrm{C}: 5 \mathrm{~min} ; 35 \times\left(94^{\circ} \mathrm{C}: 30 \mathrm{sec}, 57^{\circ} \mathrm{C} \text { : }\right. \\
\left.\quad 30 \mathrm{sec}, 72^{\circ} \mathrm{C}: 1 \mathrm{~min}\right) ; 72^{\circ} \mathrm{C}: 5 \mathrm{~min}\end{array}$ & 190 & (10) \\
\hline$b l a_{\mathrm{ADC}}$ & $\mathrm{ADC}$ & $\begin{array}{l}\text { F: TAAACACCACATATGTTCCG } \\
\text { R: ACTTACTTCAACTCGCGACG }\end{array}$ & $\begin{array}{l}94^{\circ} \mathrm{C}: 5 \mathrm{~min} ; 35 \times\left(94^{\circ} \mathrm{C}: 30 \mathrm{sec}, 57^{\circ} \mathrm{C}:\right. \\
\left.\quad 30 \mathrm{sec}, 72^{\circ} \mathrm{C}: 1 \mathrm{~min}\right) ; 72^{\circ} \mathrm{C}: 5 \mathrm{~min}\end{array}$ & 663 & (1) \\
\hline
\end{tabular}




\begin{tabular}{|c|c|c|c|c|c|}
\hline Genes & $\begin{array}{c}\text { Primer } \\
\text { names }\end{array}$ & Sequence of Primers & Annealing $\operatorname{Tm}\left({ }^{\circ} \mathbf{C}\right)$ & $\begin{array}{l}\text { Product } \\
\text { size (bp) }\end{array}$ & Ref \\
\hline bla & IMP & $\begin{array}{l}\text { F: CTACCGCAGAGTCTTTG } \\
\text { R: AACCAGTTTTGCCTTACCAT }\end{array}$ & $\begin{array}{c}94^{\circ} \mathrm{C}: 5 \mathrm{~min} ; 35 \times\left(94^{\circ} \mathrm{C}: 30 \mathrm{sec}, 62^{\circ} \mathrm{C}:\right. \\
\left.30 \mathrm{sec}, 72^{\circ} \mathrm{C}: 1 \mathrm{~min}\right) ; 72^{\circ} \mathrm{C}: 5 \mathrm{~min}\end{array}$ & 587 & (3) \\
\hline $16 s r R N A$ & 16srRNA & $\begin{array}{l}\text { F: CATTATCACGGTAATTAGTG } \\
\text { R: AGAGCACTGTGCACTTAAG }\end{array}$ & $\begin{array}{c}94^{\circ} \mathrm{C}: 5 \mathrm{~min} ; 35 \times\left(94^{\circ} \mathrm{C}: 30 \mathrm{sec}, 60^{\circ} \mathrm{C} \text { : }\right. \\
\left.30 \mathrm{sec}, 72^{\circ} \mathrm{C}: 1 \mathrm{~min}\right) ; 72^{\circ} \mathrm{C}: 5 \mathrm{~min}\end{array}$ & 288 & (3) \\
\hline
\end{tabular}

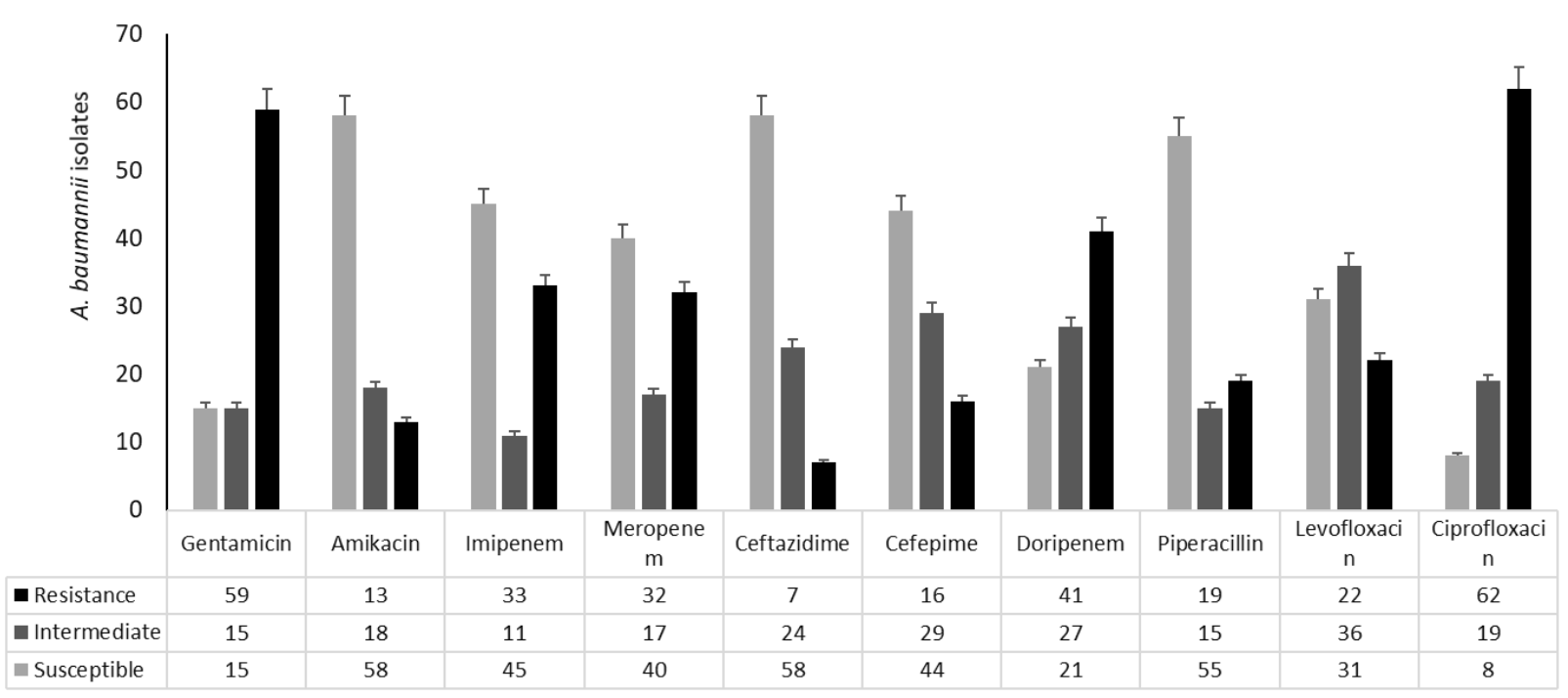

Figure 1. Antibiotic resistance pattern in wound infection isolates of $A$. baumannii
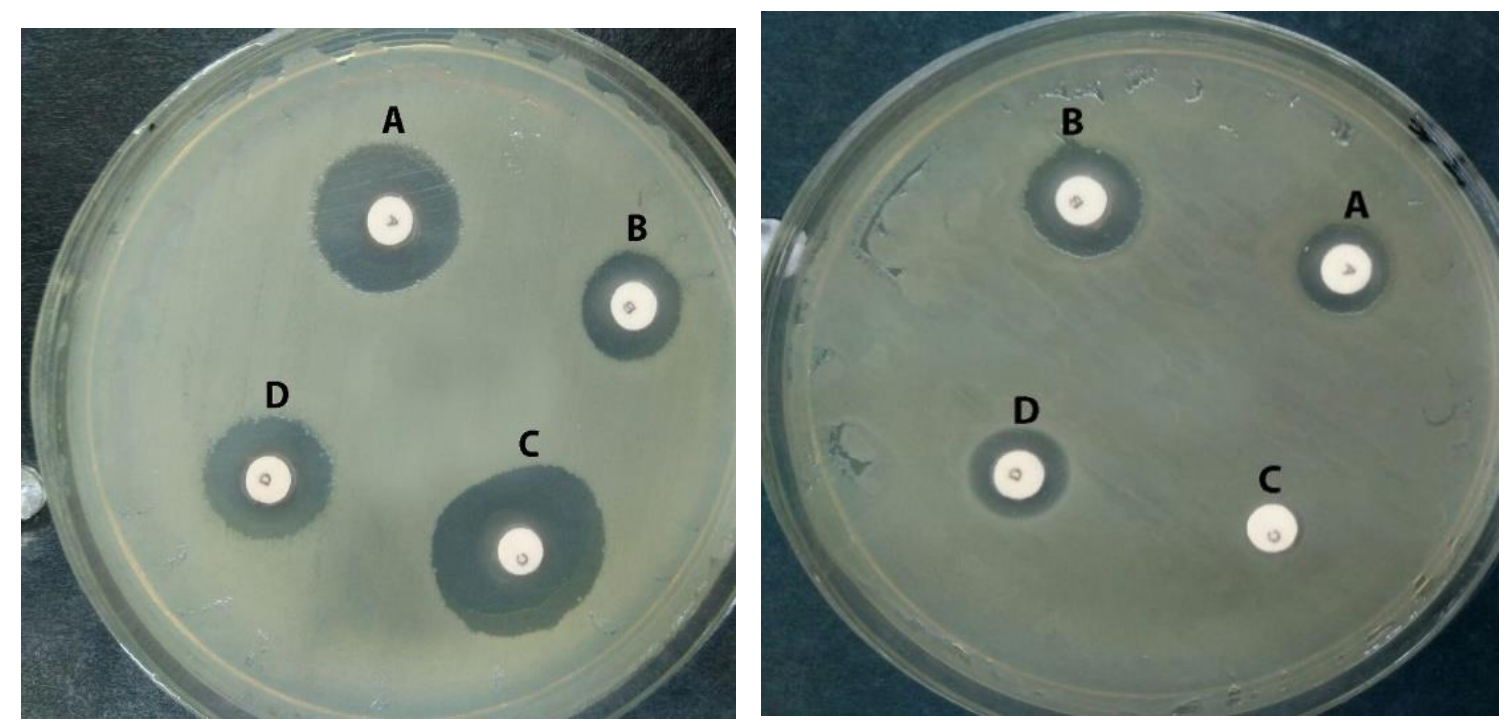

Figure 2. AmpC and ESBL-producing strains of wound infection isolates of $A$. baumannii. For ESBL producer strains: B $A$ and D-C $\geq 5 \mathrm{~mm}, \mathrm{D}-\mathrm{B}$, and $\mathrm{C}-\mathrm{A}<5 \mathrm{~mm}$. For $A m p C$ positive: $\mathrm{B}-\mathrm{A}$ and $\mathrm{D}-\mathrm{C}<5 \mathrm{~mm}, \mathrm{D}-\mathrm{B}$, and $\mathrm{C}-\mathrm{ZA} \geq 5 \mathrm{~mm}$. For $A m p C$ and ESBL-producing strains: D-C $\geq 5 \mathrm{~mm}, \mathrm{ZB}-\mathrm{ZA}<5 \mathrm{~mm}$. For $A m p C$ and $E S B L$ negative: Difference of the zones $\leq 2 \mathrm{~mm}$. 
Table 2. Correlation Between Biofilm formation, antibiotic-resistant and $\beta$-lactamase enzymes in wound infection isolates of $A$. baumannii with/without biofilm

\begin{tabular}{|c|c|c|c|c|c|c|c|c|c|c|c|c|c|c|c|c|}
\hline \multirow{2}{*}{ Antibiotics } & \multicolumn{3}{|c|}{ None } & \multicolumn{3}{|c|}{ Weak } & \multicolumn{3}{|c|}{ Moderate } & \multicolumn{3}{|c|}{ High } & \multirow{2}{*}{$\begin{array}{c}\text { P-value } \\
\text { of } \\
\text { none } \\
\text { Biofil } \\
\text { m }\end{array}$} & \multirow{2}{*}{$\begin{array}{c}\text { P-value } \\
\text { of } \\
\text { Weak } \\
\text { Biofilm }\end{array}$} & \multirow{2}{*}{$\begin{array}{c}\text { P-value } \\
\text { of } \\
\text { Moderate } \\
\text { Biofilm }\end{array}$} & \multirow{2}{*}{$\begin{array}{c}\text { P-value } \\
\text { of } \\
\text { High } \\
\text { Biofilm }\end{array}$} \\
\hline & $\mathrm{R}$ & I & $\mathrm{S}$ & $\mathrm{R}$ & I & $\mathrm{S}$ & $\mathrm{R}$ & I & $\mathrm{S}$ & $\mathrm{R}$ & I & $\mathrm{S}$ & & & & \\
\hline PIP & 0 & 0 & 13 & 0 & 0 & 10 & 0 & 0 & 10 & 19 & 15 & 2 & $P=0.9$ & $P=0.015$ & $P=0.015$ & $P=0.015$ \\
\hline DOR & 0 & 0 & 13 & 4 & 0 & 4 & 4 & 19 & 4 & 32 & 8 & 0 & $P=0.9$ & $P=0.009$ & $P=0.009$ & $P=0.009$ \\
\hline CPE & 0 & 0 & 13 & 2 & 2 & 6 & 0 & 8 & 18 & 14 & 19 & 5 & $P=0.9$ & $P=0.009$ & $P=0.009$ & $P=0.009$ \\
\hline CAZ & 0 & 1 & 12 & 0 & 4 & 6 & 4 & 3 & 20 & 3 & 17 & 17 & $P=0.1$ & $P=0.05$ & $P=0.021$ & $P=0.01$ \\
\hline MER & 0 & 0 & 13 & 0 & 4 & 6 & 4 & 11 & 12 & 29 & 1 & 15 & $P=0.9$ & $P=0.006$ & $P=0.006$ & $P=0.006$ \\
\hline IMI & 0 & 0 & 13 & 0 & 0 & 10 & 4 & 2 & 15 & 29 & 9 & 7 & $P=0.9$ & $P=0.035$ & $P=0.035$ & $P=0.035$ \\
\hline AMK & 0 & 2 & 11 & 1 & 1 & 11 & 10 & 1 & 8 & 10 & 13 & 0 & $P=0.19$ & $P=0.019$ & $P=0.019$ & $P=0.019$ \\
\hline GEN & 0 & 2 & 11 & 9 & 1 & 0 & 17 & 5 & 2 & 33 & 7 & 0 & $P=0.19$ & $P=0.003$ & $P=0.015$ & $P=0.002$ \\
\hline LVX & 0 & 0 & 13 & 0 & 10 & 0 & 4 & 10 & 10 & 20 & 16 & 8 & $P=0.9$ & $P=0.045$ & $P=0.045$ & $P=0.045$ \\
\hline CIP & 0 & & 7 & 10 & & 0 & 17 & & 1 & 35 & & 0 & $P=0.25$ & $P=0.004$ & $P=0.004$ & $P=0.004$ \\
\hline MDR & & 0 & & & 4 & & & 7 & & & 11 & & $P=0.01$ & $P=0.007$ & $P=0.04$ & $P=0.003$ \\
\hline XDR & & 1 & & & 0 & & & 4 & & & 6 & & $P=0.15$ & $P=0.00$ & $P=0.015$ & $P=0.001$ \\
\hline
\end{tabular}

\begin{tabular}{|c|c|c|c|c|c|c|c|c|}
\hline \multicolumn{9}{|c|}{$\beta$-lactamase enzymes } \\
\hline AmpC & 0 & 5 & 11 & 24 & $P=0.09$ & $P=0.012$ & $P=0.081$ & $P=0.004$ \\
\hline ESBL & 2 & 1 & 19 & 13 & $P=0.075$ & $P=0.033$ & $P=0.019$ & $P=0.009$ \\
\hline KPC & 0 & 9 & 1 & 16 & $P=0.95$ & $P=0.048$ & $P=0.028$ & $P=0.001$ \\
\hline ESBL+AmpC & 0 & 2 & 5 & 12 & $P=0.97$ & $P=0.003$ & $P=0.041$ & $P=0.004$ \\
\hline KPC+AmpC & 0 & 0 & 3 & 9 & $P=0.066$ & $P=0.043$ & $P=0.051$ & $P=0.004$ \\
\hline ESBL+KPC & 0 & 3 & 5 & 6 & $P=0.13$ & $P=0.013$ & $P=0.011$ & $P=0.009$ \\
\hline $\begin{array}{c}\text { ESBL+AmpC+ } \\
\text { KPC }\end{array}$ & 0 & 0 & 2 & 9 & & & & \\
\hline $\begin{array}{c}\text { Sensitive to all } \\
\text { antibiotics }\end{array}$ & 10 & 24 & 0 & 1 & $P=0.04$ & $P=0.090$ & $P=0.17$ & $P=0.25$ \\
\hline \multicolumn{9}{|c|}{$\beta$-lactamase genes } \\
\hline blaFOX & 0 & 6 & 2 & 18 & $P=0.95$ & $P=0.09$ & $P=0.007$ & $P=0.005$ \\
\hline blaADC & 1 & 0 & 5 & 21 & $P=0.25$ & $P=0.015$ & $P=0.84$ & $P=0.001$ \\
\hline blaVEB & 2 & 0 & 19 & 10 & $P=0.76$ & $P=0.070$ & $P=0.024$ & $P=0.064$ \\
\hline blaPER & 0 & 0 & 18 & 11 & $P=0.09$ & $P=0.045$ & $P=0.017$ & $P=0.002$ \\
\hline blaIMP & 0 & 0 & 6 & 19 & $P=0.085$ & $P=0.020$ & $P=0.009$ & $P=0.005$ \\
\hline blaKPC & 5 & 0 & 1 & 17 & $P=0.012$ & $P=0.015$ & $P=0.024$ & $P=0.001$ \\
\hline
\end{tabular}



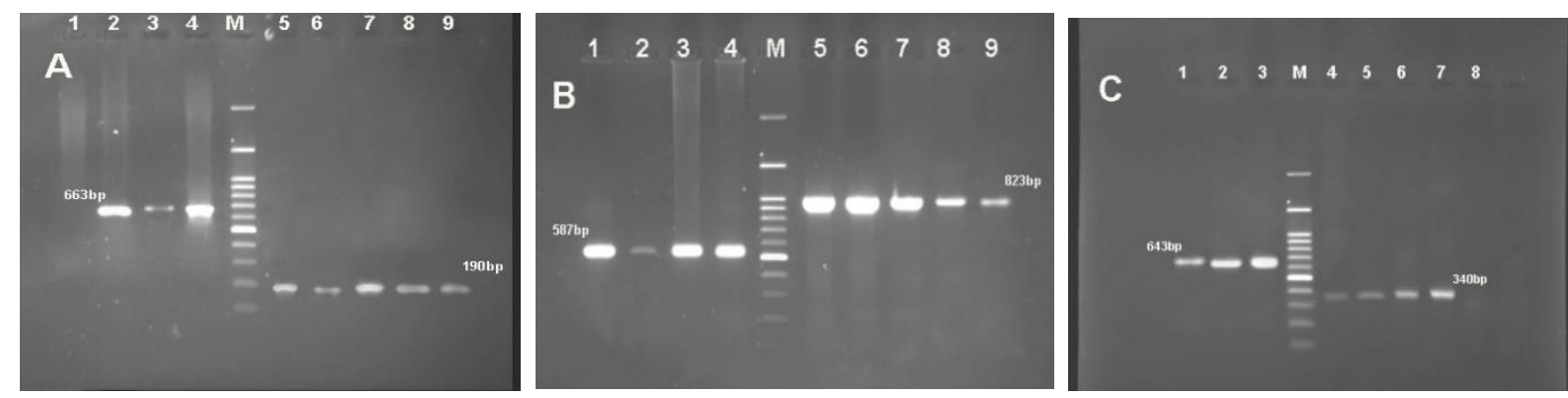

Figure 3. The amplification and gel electrophoresis agarose $2 \%$ of $\beta$-lactamase genes. A: blaFOX with $190 \mathrm{bp}$, blaADC with 663bp. B: blaIMP with 587bp, bla KPC with 823bp. C: blaPER with 340bp and blaVEB with 643bp. M: Ladder 100bp.

\section{Discussion}

A. baumannii is the main cause of nosocomial infection and is often responsible for the high frequency of wound infections among hospitalized patients. However, some virulence factors such as biofilms play a key role in the emergence of MDR strains (6).

The present study indicated a high rate of carbapenems (29.21\%), gentamycin (69.66\%), and ciprofloxacin $(66.29 \%)$ among the A. baumannii isolates (Table 2). The results are consistent with those of Uwingabiye et al. in 2016 (6) and Chen et al. in 2017 (19). Further, the present study confirmed a low rate of ceftazidime $(7.86 \%)$ and amikacin $(14.77 \%)$ resistant strains, which contradicts the results of Almaghrabi et al. in 2018 (20) and Simo Tchuinte et al. in 2019 (21) indicating a high rate of amikacin-resistant strains. In addition, several studies reported that the prevalence of A. baumannii resistant to amikacin, ceftazidime, and cefepime was higher than that to ticarcillin, piperacillin, and ciprofloxacin-resistant strains $(\mathbf{1 , 6 , 2 2 )}$.

Moreover, MDR strains were reported in $31.42 \%$ of the isolates used in the present study, which is consistent with the results of Kuti et al. (23). However, a possible reason for the bacterial co-resistance is plasmids, carrying antimicrobial resistance genes and even virulence gene many of which easily transfer between the bacteria from different sources and geographical origins.

As presented in Table 2, the frequency of AmpC, ESBL, and KPC-producing A. baumannii is 34.83, 44.94, and 24.71\%, respectively. However, some studies in China (1), India (5), and Egypt (24) reported over $70 \%$ of AmpC, ESBL, and KPC-producing A. baumannii. Further, the co-existence of AmpC and ESBL, AmpC and KPC, and ESBL and KPC enzymes was detected in $21.34,13.48$, and $15.73 \%$ of the isolates, respectively, which is in line with the results of Kumar et al. (25), Begum et al. (26), and Khajuria et al. (27). Other studies indicated that AmpC enzyme could increase the frequency of ESBL and KPC-producing $A$. baumannii and have an effect on carbapenem and $\beta$ lactam antibiotics with the help of some amino acids (5, 28).
The present study demonstrated that blaVEB, blaPER, blaFOX, and the blaADC genes were found in $29.21,34.83,29.21$, and $30.33 \%$ of the isolates, respectively. This finding is very similar to those reported by Fallah et al. (2), Al-Agamy et al. (11), and Shacheraghi et al. (29). The low frequency of blaIMP and blaKPC genes in A. baumannii isolates was reported by Chang et al. (3) and Alkasaby et al. (30). On the contrary, the high frequency of $A m p C$ and $E S B L$ genes was observed in some studies in India (5), Iran (2), Egypt (11,30), and Brazil (31). This difference and the high resistance may be due to the ability of the organism to produce more than one hydrolyzing enzyme, show modifications in more than one outer membrane porin channel, or select the pressure. Accordingly, the large diversity found in the data of the present study could be the result of evolution of the ancestral gene, rather than the foreign carriage of the clones into the country.

Table 2 indicates that $22.47 \%$ of the isolates are classified as strong biofilms and $21.34 \%$ as moderate biofilms. As can be seen, the frequency of $\beta$-lactamase genes in biofilm-forming strains is higher than the nonbiofilm-forming A. baumannii. Thus, in line with the results of Yang et al. (32), biofilm formation in $A$. baumannii isolated from the wound can affect the frequency of $\beta$-lactamase genes. The results of the study conducted by Rahimi et al. (7) support those of the present study indicating that biofilm-forming $A$. baumanii had relatively higher resistance to amikacin compared to non-biofilm-forming strains. In addition, a strong relationship was observed between biofilm formation and $\beta$-lactamase enzymes in MDR-XDR strains. Lee et al. (33) and Rao et al. (8) demonstrated that blaPER gene was strongly correlated with biofilm formation in A. baumannii and was the most abundant gene in biofilm-forming strains.

Furthermore, non-biofilm-forming strains are more sensitive to fluoroquinolone and carbapenem compared to the biofilm-forming strains, as shown in Table 2. This result is inconsistent with those of Avila-Novoa et al. (34), who found that high concentrations of imipenem and ciprofloxacin led to the death of biofilm-producing bacteria. In another study, Qi et al. (35) stated that low 
fluoroquinolone concentrations had a signifanct effect on eliminating biofilm.

In the present study, a significant correlation between $\beta$-lactamase enzymes and biofilm formation in $A$. baumannii was observed. Similarly, Hatami Moghadam et al. (9) found that the biofilm formation and antibiotic resistance in $A$. baumannii isolated from the wound were significanlty correlated. However, these results are inconsistent with those of Wang et al. (36), who indicated that there was no significant correlation between $\beta$-lactamase enzymes and the biofilm formation in A. baumannii bacteremic pneumonia. It should be noted that this correlation depends on several factors, among which the clinical sample type is considered very critical. Therefore, the variety of clinical samples plays an important role in this regard. However, the results of the present study confirmed that physical, chemical, and biological processes could regulate the formation of biofilms. Various environmental conditions influence the creation, composition, and preservation of a biofilm. These factors have a direct effect on the resistance to antibiotics. Accordingly, antibiotics may lose their effectiveness if an organism stops growing due to lack of nutrients or substrates since certain antibiotics, such as penicillin, only target growing organisms $(37,38)$. Thus, the pressure of stressors can permanently alter the antimicrobial resistance in bacteria and these factors can influence the biofilm formation in wound infection.

\section{Conclusion}

The results obtained in the present study revealed that the A. baumannii biofilm producer was more resistant to different antibiotics. In addition, a significant correlation was found between $\beta$-lactamase enzymes and biofilm formation in A. baumannii isolates. Further, antibiotic resistance profile had a significant correlation with biofilm formation. The results suggested that the biofilm-forming strains were more potent against antimicrobial drugs.

Therefore, A. baumannii isolated from the wounds is more prone to biofilm formation, and therefore antibiotic resistance can be more prevalent in wound infections. The biofilms in the wound infections of $A$. baumannii are considered as an essential factor in spreading the MDR strains and pose a serious risk to patients. It is crucial to evaluate the prevalence of MDR strains in wound infections since this probably indicates the emergence of adaptative resistance during the wound infection and possible problems in the treatment.

\section{Acknowledgments}

The authors gratefully thank Islamic Azad University, Hamadan, Iran, for providing facilities to conduct the research. This study was funded by the Research Deputy of Islamic Azad University, Hamadan, Iran (Grant No. 17130507962001)

\section{Conflict of Interest}

Authors declared no conflict of interest.

\section{References}

1. Liu Y, Liu X. Detection of AmpC $\beta$ lactamases in Acinetobacter baumannii in the Xuzhou region and analysis of drug resistance. Exp Ther Med. 2015;10(3):933-6. [DOI: 10.3892/etm.2015.2612] [ PMID: 26622417]

2. Fallah F, Noori M, Hashemi A, et al. Prevalence of bla NDM, bla PER, bla VEB, bla IMP, and bla VIM Genes among Acinetobacter baumannii isolated from two hospitals of Tehran, Iran. Scientifica. 2014;2014:245162-.[DOI: 10.1155/2014/245162] [PMID: 25133013]

3. Chang Y, Luan G, Xu Y, et al. Characterization of carbapenem-resistant Acinetobacter baumannii isolates in a Chinese teaching hospital. Front Microbiol. 2015;6:910-.doi: 10.3389/fmicb.2015.00910. 10.3389/fmicb.2015.00910] [PMID: 26388854].

4. Tahmasebi H, Maleki F, Dehbashi S, Arabestani MR. Role and function of KPC and MBL enzymes in increasing the pathogenicity of pseudomonas aeruginosa isolated from burn wounds. $J$ Babol Univ Med Sci. 2019;21(1):127-34.

5. Singla P, Sikka R, Deeep A, Gagneja D, Chaudhary U. Co-production of ESBL and AmpC $\beta$ lactamases in Clinical isolates of $A$. baumannii and A. lwoffii in a tertiary care hospital from Northern India. J Clin Diag Res. 2014;8(4):DC16-DC9. [DOI: 10.7860/JCDR/2014/8008.4289] [PMID: 24959443]

6. Uwingabiye J, Frikh M, Lemnouer A, et al. Acinetobacter infections prevalence and frequency of the antibiotics resistance: comparative study of intensive care units versus other hospital units. Pan African Med J. 2016;23:191. [DOI: 10.11604/pamj.2016.23.191.7915] [PMID: 27347280]

7. Rahimi S, Farshadzadeh Z, Taheri B, Mohammadi M, Haghighi M, Bahador A. The relationship between antibiotic resistance phenotypes and biofilm formation capacity in clinical isolates of Acinetobacter baumannii. Jundishapur J Microbiol. 2018;11(8):e74315. [DOI: 10.5812/jjm.74315].

8. Rao RS, Karthika RU, Singh SP, et al. Correlation between biofilm production and multiple drug resistance in imipenem resistant clinical isolates of Acinetobacter baumannii. Indian J Med Microbiol. 2008;26(4):333-7. [ PMID:18974485]

9. Hatami Moghadam R, Alvandi A, Akbari N, Jafari P, Abiri R. Assessment of biofilm formation among clinical isolates of Acinetobacter baumannii in burn wounds in the west of Iran. Cell Mol Biol (Noisyle-grand). 2018;64(15):30-4. [PMID: 30672433] 
10. Dehbashi S, Tahmasebi H, Arabestani MR. Association between Beta-lactam Antibiotic resistance and virulence factors in $\mathrm{AmpC}$ producing clinical strains of P. aeruginosa. Osong Public Health Res Perspect. 2018;9(6):325-33. [DOI:
[D. 10.24171/j.phrp.2018.9.6.06] [PMID: 30584496]

11. Al-Agamy MH, Khalaf NG, Tawfick MM, Shibl AM, Kholy AE. Molecular characterization of carbapenem-insensitive Acinetobacter baumannii in Egypt. Int $J$ Infect Dis. 2014;22:49-54. [DOI: 10.1016/j.ijid.2013.12.004] [PMID: 24607428].

12. Bush K, Jacoby GA. Updated functional classification of beta-lactamases. Antimicrob Agents Chemother. 2010;54(3):969-76.
[DOI: 10.1128/AAC.01009-09] [PMID: 19995920]

13. Tahmasebi H, Dehbashi S, Arabestani MR. High resolution melting curve analysis method for detecting of carbapenemases producing pseudomonas aeruginosa.J Krishna Inst Med Sci Univ. 2018;7(4):707.

14. Moubareck C, Bremont S, Conroy MC, Courvalin P, Lambert T. GES-11, a novel integronassociated GES variant in Acinetobacter baumannii. Antimicrob Agents Chemother. 2009;53(8):3579-81. [DOI: 10.1128/aac.00072-09] [PMID: 19451292]

15. Poirel L, Menuteau O, Agoli N, Cattoen C, Nordmann P. Outbreak of extended-spectrum betalactamase VEB-1-producing isolates of Acinetobacter baumannii in a French hospital. J Clin Microbiol. 2003;41(8):3542-7. [DOI: 10.1128/jcm.41.8.35423547.2003] [PMID: 12904353]

16. Tahmasebi H, Yousef Alikhani M, Dehbashi $\mathrm{S}$, Arabestani MR. Investigation of the relationship between the presence of chromosomal and plasmidencoded ampc genes and type of clinical specimen in pseudomonas aeruginosa. J Babol Univ Med Sci. 2018;20(3):36-43.

10.18869/acadpub.jbums.20.3.36]

17. Clinical and Laboratory Standards Institute. 2018. Methods for dilution antimicrobial susceptibility tests for bacteria that grow aerobically; approved standard-10th ed. M07-A11. Clinical and Laboratory Standards Institute, Wayne, PA

18. Ghadaksaz A, Imani Fooladi AA, Hosseini HM, Amin M. The prevalence of some Pseudomonas virulence genes related to biofilm formation and alginate production among clinical isolates. J Apply Biomed. 2015;13(1):61-8. [DOI: 10.1016/j.jab.2014.05.002].

19. Chen LK, Kuo SC, Chang KC, et al. Clinical antibiotic-resistant Acinetobacter baumannii strains with higher susceptibility to environmental phages than antibiotic-sensitive strains. Sci Rep. 2017;7(1):6319.[DOI: 10.1038/s41598-017-06688-w] [PMID: 28740225]

20. Almaghrabi MK, Joseph MRP, Assiry MM, Hamid ME. Multidrug-resistant Acinetobacter baumannii: An emerging health threat in aseer region, Kingdom of Saudi Arabia. Canadian J Infect Dis Med Microbiol. 2018;2018:4.

[DOI: 10.1155/2018/9182747] [PMID: 29623140]
21. Simo Tchuinte PL, Rabenandrasana MAN, Kowalewicz C, et al. Phenotypic and molecular characterisations of carbapenem-resistant Acinetobacter baumannii strains isolated in Madagascar. Antimicrob Resist Infect Control. 2019;8(1):31.[DOI: 10.1186/s13756-019-0491-9] [PMID: 30792853].

22. Xie R, Zhang XD, Zhao Q, Peng B, Zheng J. Analysis of global prevalence of antibiotic resistance in Acinetobacter baumannii infections disclosed a faster increase in OECD countries. Emerg Microbes Infect. 2018;7(1):31-. [DOI: 10.1038/s41426-0180038-9] [ PMID: 29535298].

23. Kuti JL, Wang Q, Chen H, Li H, Wang H, Nicolau DP. Defining the potency of amikacin against Escherichia coli, Klebsiella pneumoniae, Pseudomonas aeruginosa, and Acinetobacter baumannii derived from Chinese hospitals using CLSI and inhalation-based breakpoints. Infect Drug Resistance. 2018;11:783-90. [DOI: 10.2147/IDR.S161636] [PMID: 29872328].

24. Ramadan RA, Gebriel MG, Kadry HM, Mosallem A. Carbapenem-resistant Acinetobacter baumannii and Pseudomonas aeruginosa: characterization of carbapenemase genes and E-test evaluation of colistin-based combinations. Infect Drug Resist. 2018;11:1261-9. [DOI: 10.2147/idr.s170233] [ PMID: 30197524].

25. Kumar E, Usha K, Chaudhury A, Ramana BV, Gopal DVRS. Detection of AmpC $\beta$-lactamases production in Acinetobacter species by inhibitor (disk) based \& modified three dimensional (enzyme extraction) methods. IndianJ Med Res. 2014;140(5):688-90. [ PMID: 25579154].

26. Begum S, Hasan F, Hussain S, Ali Shah A. Prevalence of multi drug resistant Acinetobacter baumannii in the clinical samples from Tertiary Care Hospital in Islamabad, Pakistan. Pakistan J Med Sci. 2013;29(5):1253-8. [ PMID: 24353731]

27. Khajuria A, Praharaj AK, Kumar M, Grover N. Molecular characterization of carbapenem resistant isolates of Acinetobacter baumannii in an intensive care unit of A Tertiary Care Centre at Central India. $J$ Clin Diag Res. 2014;8(5):DC38-DC40. [DOI: 10.7860/JCDR/2014/7749.4398] [ PMID: 24995182]

28. Lai JH, Yang JT, Chern J, et al. Comparative phosphoproteomics reveals the role of AmpC $\beta$ lactamase phosphorylation in the clinical imipenemresistant strain Acinetobacter baumannii SK17. Mol Cell Proteomics. 2016;15(1):12-25. [DOI: 10.1074/mcp.M115.051052] [ PMID: 26499836] 29. Shacheraghi F, Shakibaie MR, Noveiri H. Molecular identification of ESBL genes blaGES-1 blaVEB-1, blaCTX-M blaOXA-1, blaOXA-4, blaOXA-10 and blaPER-1 in Pseudomonas aeruginosa strains isolated from burn patients by PCR, RFLP and sequencing techniques. Int J Biol Life Sci. 2010;6:13842. [DOI: doi.org/10.5281/zenodo.1327919]

30. Alkasaby NM, El Sayed Zaki M. Molecular study of Acinetobacter baumannii isolates for metallo$\beta$-lactamases and extended-spectrum- $\beta$-lactamases 
genes in intensive care unit, Mansoura University Hospital, Egypt. Int J Microbiol. 2017;2017:3925868.[DOI: 10.1155/2017/3925868] [ PMID: 28567057]

31. Ribeiro PCS, Monteiro AS, Marques SG, et al. Phenotypic and molecular detection of the blaKPC gene in clinical isolates from inpatients at hospitals in São Luis, MA, Brazil. BMC Infect Dis. 2016;16(1):737. [DOI: 10.1186/s12879-016-2072-3][ PMID: 27927163]

32. Yang $\mathrm{CH}$, Su PW, Moi SH, Chuang LY. Biofilm formation in Acinetobacter Baumannii: genotype-phenotype correlation. Molecules. 2019;24(10):1849. [DOI: 10.3390/molecules24101849] [ PMID: 31091746]

33. Lee HW, Koh YM, Kim J, et al. Capacity of multidrug-resistant clinical isolates of Acinetobacter baumannii to form biofilm and adhere to epithelial cell surfaces. Clin Microbiol Infect. 2008;14(1):49-54. [DOI: 10.1111/j.1469-0691.2007.01842.x][ PMID: 18005176]

34. Avila-Novoa M, Solís-Velázquez OA, Rangel-López DE, González-Gómez JP, GuerreroMedina PJ, Gutiérrez-Lomelí M. Biofilm formation and detection of fluoroquinolone- and carbapenemresistant genes in multidrug-resistant Acinetobacter baumannii. Can $J$ Infect Dis Med Microbiol. 2019;2019:1-5.[DOI: 10.1155/2019/3454907].

35. Qi L, Li H, Zhang C, et al. Relationship between antibiotic resistance, biofilm formation, and biofilm-specific resistance in Acinetobacter baumannii. Front Microbiol. 2016;7:483. [DOI: 10.3389/fmicb.2016.00483] [ PMID: 27148178]

36. Wang YC, Huang TW, Yang YS, et al. Biofilm formation is not associated with worse outcome in Acinetobacter baumannii bacteraemic pneumonia. Sci Rep. 2018;8(1):7289. [DOI: 10.1038/s41598-018-25661-9] [ PMID: 29740176]

37. Kiamco MM, Atci E, Mohamed A, Call DR, Beyenal H. Hyperosmotic agents and antibiotics affect dissolved oxygen and $\mathrm{PH}$ concentration gradients in Staphylococcus aureus biofilms. Appl Environ Microbiol. 2017;83(6). pii: e02783-16. [DOI: 10.1128/aem.02783-16] [ PMID: 28062458]

38. Cohen BE. Functional linkage between genes that regulate osmotic stress responses and multidrug resistance transporters: challenges and opportunities for antibiotic discovery. Antimicrob Agents Chemother. 2014;58(2):640-6. [DOI:
[DI 10.1128/AAC.02095-13] [ PMID: 24295980]

\title{
How to Cite This Article:
}

Porbaran M, Habibipour R. Biofilm Formation and $\beta$-lactamase Enzymes: A Synergism Activity in Acinetobacter baumannii Isolated from Wound Infection. J Adv Med Biomed Res. 2019; 27 (125) :34-42

\section{Download citation:}

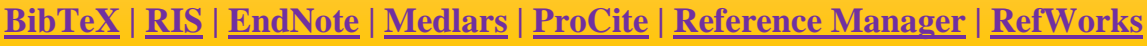

\section{Send citation to:}

\author{
Mendelev 2 Zotero 国efWorks $\underline{\text { RefWorks }}$
}

